\title{
CRÍTICA DE MARX À METAFÍSICA DA ECONOMIA POLÍTICA
}

\author{
Adauto Lopes da Silva Filho ${ }^{1}$ \\ Universidade Federal do Ceará (UFC) \\ https://orcid.org/0000-0001-9061-840X \\ E-mail: adautoufcfilosofia@gmail.com \\ Fátima Maria Nobre Lopes ${ }^{2}$ \\ Universidade Federal do Ceará (UFC) \\ http://orcid.org/0000-0003-4602-2443 \\ E-mail: fatimanobreufc@gmail.com
}

\section{RESUMO:}

Ao desenvolver a sua concepção materialista da história, Marx elabora, ao mesmo tempo, uma crítica ao pensamento hegeliano acompanhada de uma crítica à economia política. Tais críticas estão condensadas principalmente em suas obras de juventude, dentre elas destaca-se a Miséria da Filosofia. O presente texto objetiva, a partir dessa obra, dissertar sobre a metafísica da economia política cuja crítica dirige-se principalmente à Proudhon, em resposta à sua obra Filosofia da Miséria na qual Proudhon, tenta, num viés metafísico, fornecer as bases para os problemas sociais, através da aplicação da dialética de Hegel ao método da economia política. Para Marx, a ideologia proudhoniana expressa em tal obra apresenta-se totalmente reformista e utópica. Em contraposição ao pensamento de Proudhon, e simultaneamente explicitando os fundamentos constitutivos da teoria do ser social tecido pelo modo de produção capitalista, Marx publica em 1847 a sua obra Miséria da Filosofia em resposta à Filosofia da Miséria de Proudhon.

PalavraS-ChAVE: História; Economia Política; Método Metafísico.

\section{THE CRITIQUE OF MARX TO THE METAPHYSICS OF POLITICAL ECONOMY}

\begin{abstract}
:
In developing his materialist conception of history, Marx creates, at the same time, a critique to the Hegelian thought next to a critique of political economy. Those critiques are mainly concentrate in his works written throughout his youth, in particular the Misery of Philosophy. Based on this work of Marx, the present paper aims to discourse on the metaphysics of political economy, whose critique is directed mainly to Proudhon responding to the work Philosophy of Misery, in which Proudhon tries to provide, in a metaphysical bias, the bases for the social problems, applying the Hegelian dialectic to the method of political economy. For Marx, the Proudhonist ideology, which is expressed in that work, is totally reformist and utopian. In contrast to the Proudhonist thought, and explaining simultaneously the foundations that constitute the theory of social being, which is woven by the capitalist mode of production, Marx publishes in 1847 his work the Misery of Philosophy in response to Proudhon's Philosophy of Misery.
\end{abstract}

KEYWORDS: History; Political Economy; Metaphysical Method.

\footnotetext{
${ }^{1}$ Doutor em educação pela Universidade Federal do Ceará (UFC), Fortaleza - CE, Brasil e mestre em Filosofia pela Universidade Federal da Paraíba (UFPB), João Pessoa - PB, Brasil. Professor da Universidade Federal do Ceará (UFC), Fortaleza - CE, Brasil

${ }^{2}$ Doutora em educação pela Universidade Federal do Ceará (UFC), Fortaleza - CE, Brasil e mestra em Filosofia pela Universidade Federal da Paraíba (UFPB), João Pessoa - PB, Brasil. Professora da Universidade Federal do Ceará (UFC), Fortaleza - CE, Brasil.
}

FILHO, Adauto Lopes da Silva; LOPES, FÁTIMA Maria Nobre. Crítica de Marx à metafísica da economia política. Griot : Revista de Filosofia, Amargosa - BA, v.18, n.2, p.271-280, dezembro, 2018 


\title{
Introdução: a Ideologia Alemã como prolegômenos à critica da economia política
}

Neste artigo trataremos especificamente acerca da crítica de Marx a Proudhon, ao que ele chama de metafísica da economia política, expressa na sua obra Miséria da Filosofia. Aqui a sua crítica, em conjunto com outras dirigidas aos hegelianos, torna-se um dos ingredientes que irá subsidiar a sua concepção de história cuja pedra angular consiste na acepção de que o homem é sujeito e autor da sua vida social e, por conseguinte, da sua própria história.

Portanto, em cada etapa do pensamento de Marx, desde as suas obras de juventude, ao exercer uma crítica ao pensamento hegeliano acompanhada de uma crítica à economia política, ele vai evidenciando a sua concepção materialista da história e, ao mesmo tempo, segue explicitando os fundamentos constitutivos da teoria do ser social tecido pelo modo de produção capitalista. Porém é mais precisamente a partir da sua obra Ideologia Alema $\tilde{a}^{3}$ que Marx expõe de forma clara e concisa uma concepção de história da sociedade humana, resultando numa nova concepção do ser dos homens e do mundo social. Aqui ele já fala do papel decisivo da inter-relação entre as forças produtivas e as relações de produção na vida social dos homens, destacando a produção como sendo a condição fundamental de toda a história humana.

Nesse sentido, a Ideologia Alemã foi uma espécie de prolegômenos à sua análise e crítica da economia política, pois antes de criticar as teorias econômicas, Marx percebeu que era necessário fazer uma exposição crítica das bases metodológicas das modernas teorias filosóficas, sociais e econômicas, como ele mesmo afirma em uma carta a Carl Leske:

\begin{abstract}
Pareceu-me, nomeadamente, muito importante publicar primeiro, antes do meu desenvolvimento positivo [do tema], um escrito polêmico contra a filosofia alemã e contra o socialismo alemão que a segue. Isto é necessário para preparar o público para o ponto de vista da minha economia que se contrapõe diretamente à ciência alemã de até agora (MARX, apud FEDOSSEIEV, 1983, p. 108. Os grifos são do autor).
\end{abstract}

A crítica de Marx ao idealismo alemão se complementava, então, com a crítica e o estudo sobre os problemas da economia política. Para ele, é impossível compreender a estrutura da sociedade, bem como as mudanças sociais, sem chegar às causas econômicas que a determinam. Dessa forma critica as lacunas da metodologia e da análise dos teóricos da economia política. $O$ caráter de tal análise revelava-se como metafísico e anti-histórico uma vez que os economistas consideravam as categorias econômicas como eternas e imutáveis. Esse era o erro metodológico básico de todos eles.

\section{A Miséria da Filosofia: uma crítica à metafísica da economia política}

Com a pretensão de abalar os fundamentos das ciências sociais e fornecer as bases para a resolução dos problemas da sociedade, através da aplicação da dialética

\footnotetext{
${ }^{3}$ Kolakowski comenta que a Ideologia alemã, cuja idéia central é a relação entre o pensamento e as condições de vida, contém "a base da interpretação materialista da história, que foi posteriormente desenvolvida com todo detalhe" (KOLAKOWSKI, 1980, p. 158).
} 
de Hegel ao método da economia política, Proudhon publicou, em 1846, uma das suas mais relevantes obras com o título Sistema das Contradições Econômicas ou Filosofia da Miséria. Ao conhecer essa ideologia de Proudhon, que se pretendia reformista, Marx tratou logo de defender a ideia do comunismo que havia sido denegrida por esse pensador e iniciou um trabalho anti-Proudhon, na tentativa de, em oposição aos dogmas proudhonistas, apresentar as bases de uma nova concepção do mundo, histórica e materialista, publicando sua obra, em 1847, com o título Miséria da Filosofia: resposta à Filosofia da Miséria do Sr. Proudhon.

Nessa obra Marx aponta o erro metodológico dos teóricos da economia política, apesar de sua crítica dirigir-se principalmente a Proudhon ${ }^{4}$ que, ao tentar aplicar o método dialético de Hegel à economia política, terminou por adulterar a própria filosofia de Hegel, reduzindo, inclusive, a economia política a um esquema de abstrações do espírito, ou seja, reduzindo a economia à categorias lógicas. Daí porque o seu método de análise das categorias econômicas é metafísico.

Marx diz que na Filosofia da Miséria Proudhon, ao examinar as contradições do capitalismo, apresenta soluções não mais que reformistas e utopistas uma vez que não compreende o caráter histórico-social das mesmas contradições que se propôs a examinar na referida obra. Como exemplo, temos o fato de ele falar em natureza humana como sendo imutável no decorrer da história. Diz Marx (1982, p. 138): “O Sr. Proudhon ignora que toda história não é mais que uma transformação contínua da natureza humana"5. Numa carta a Annenkov, Marx diz que os economistas burgueses não compreendem as contradições do capitalismo; "nenhum deles compreende que a forma burguesa de produção é uma forma histórica e transitória, como era a forma feudal" (MARX, "Carta à P.V. Annenkov", anexo à Miséria da Filosofia, 1982, p. 213).

A oposição de Marx a Proudhon refere-se principalmente ao fato de este adotar pontos de vista moralistas na análise das categorias econômicas. Proudhon acreditava numa harmonia natural da sociedade e nos imprescindíveis direitos humanos que eram violados pelo sistema social vigente. Tais direitos eram partes do destino dos homens, prescrito pela vontade de Deus. Até mesmo as categorias econômicas eram consideradas princípios eternos, como ele próprio afirma: não é correto dizer "que qualquer coisa acontece, que qualquer coisa se produz: na civilização, como no universo, tudo existe, tudo atua desde sempre [...] o mesmo acontece com toda a economia social" (PROUDHON, apud MARX, 1982, p. 111. Grifos do autor).

Marx comenta que para o autor já não há história, e sim uma sucessão de ideias que culmina na razão geral, como gênio social, da qual o Senhor Proudhon

\footnotetext{
${ }^{4}$ Proudhon, partidário dos utopistas socialistas, fez um programa de reforma social no qual invocava idéias de justiça e igualdade, também foi o criador da expressão "o socialismo científico". Para ele, o sistema de competição, desigualdade e exploração é incompatível com os direitos humanos prescritos pela própria vontade divina. Ficou conhecido pela sua frase "a propriedade é um roubo", porém as medidas que ele apresentava para solucionar as contradições do capitalismo não era a extinção da propriedade privada e sim ela deveria ser estendida a todos os homens (dessa forma, acabava-se apenas com o monopólio da propriedade privada), e isso seria possível se fossem abolidos os lucros resultantes do trabalho e se fosse criado um sistema de troca em que cada produtor deveria receber o equivalente à sua produção. Com isso, seria eliminado o lado mau do capitalismo, pois, segundo Proudhon, toda categoria econômica tem dois lados: o bom e o mau. Essa sua posição baseia-se na dialética de Hegel, no entanto é contra a síntese do movimento dialético. (Sobre essa questão ver Leszek Kolakowski na sua obra: La principales corrientes del marxismo,1980. p. 207 a 214).

${ }^{5} \mathrm{Na}$ Introdução de Paulo Neto à edição desta obra a qual estamos fazendo referências, ele cita a posição de Proudhon acerca da história das sociedades, que se manifesta "como uma longa determinação de Deus, uma revelação progressiva do destino do homem" (1982, p. 17).
} 
pretende ser a encarnação. Então as suas ideias estavam enraizadas na natureza humana e sua realização não seria mais que o cumprimento do destino humano. Diz Proudhon, citado por Marx (1982, p. 102. Grifos do autor):

\begin{abstract}
Não fazemos uma história segundo a ordem temporal, mas segundo a sucessão das idéias. As fases ou categorias econômicas são, em sua manifestação, ora contemporâneas, ora invertidas [...] As teorias econômicas nem por isto deixam de ter sua sucessão lógica e sua série no entendimento: é esta ordem que nos orgulhamos de ter descoberto.
\end{abstract}

Marx comenta que Proudhon lança aí frases "quase hegelianas". Por isso tem que verificar os dois homens: primeiro o Sr. Proudhon, depois Hegel ${ }^{6}$.

Quanto à Proudhon, este leva desvantagens até mesmo em relação aos outros economistas. Segundo Marx, os outros economistas pecam ao exprimirem as relações burguesas de produção (a divisão do trabalho, a moeda, o crédito, etc.) como categorias eternas, fixas, imutáveis. Porém, Proudhon tem à sua frente estas categorias já formadas e quer explicá-las quanto à sua geração, os seus princípios, suas leis e ideias. De certa forma, os economistas levam vantagem em relação à Proudhon, visto que estão mais próximos da matéria trabalhada, isto é, os seus materiais "são a vida ativa e atuante; os materiais do Sr. Proudhon são os dogmas dos economistas" (MARX, 1982, p. 102). Mesmo com certo limite, os economistas explicam como se dá a produção dentro do processo da sociedade burguesa. Contudo, falta-lhes ainda a perspectiva histórica, uma vez que transformam as relações de produção, historicamente determinadas, em relações necessárias, válidas para qualquer tempo. Já Proudhon, tomando estas relações como princípios, pensamentos abstratos, tem apenas que ordenar esses pensamentos. $O$ fato é que Proudhon tenta aplicar o movimento às relações de produção utilizando-se da dialética de Hegel, sem ter compreendido que a sua aplicação científica à análise dos fenômenos econômicos pressupõe a revelação das contradições inerentes a estes mesmos fenômenos.

\begin{abstract}
A partir do momento em que não se persegue o movimento histórico das relações de produção, de que as categorias são apenas a expressão teórica, a partir do momento em que se quer ver nestas categorias somente ideias, pensamentos espontâneos, independentes das relações reais, a partir de então se é forçado a considerar o movimento da razão pura como a origem desses pensamentos (MARX, idem, p. 102-103).
\end{abstract}

Proudhon, com um conhecimento muito limitado da dialética de Hegel, apresenta as relações econômicas no estado de categorias lógicas. Para ele, "as coisas aqui da Terra são bordadas, cujo pano-de-fundo é constituído pelas categorias lógicas [...] $\mathrm{O}$ que Hegel fez em relação à religião, ao direito, etc., o Sr. Proudhon procura fazer em relação à economia política" (MARX, idem, p. 103-104).

Ora, para Marx, as categorias econômicas exprimem as formas do ser, exprimem as determinações da existência. No entanto, Proudhon vê nas relações reais apenas encarnações de princípios abstratos. Proudhon, como economista, compreendeu que os homens produzem tecidos de algodão, linho, etc., dentro de determinadas relações de produção, "mas o que ele não compreendeu é que estas relações sociais determinadas são também produzidas pelos homens, como os tecidos

\footnotetext{
${ }^{6}$ Embora a crítica de Marx, na obra que estamos tratando, refira-se à Proudhon, em algumas passagens ele remete a Hegel, até mesmo para demonstrar as falhas de Proudhon ao tentar utilizar a dialética de Hegel.
} 
de algodão, linho e etc." (MARX, idem, p. 106). Segundo Marx, ao adquirir novas formas produtivas, os homens transformam o seu modo de produção e, ao transformá-lo, alteram também as suas relações sociais. Os homens, ao produzir as relações sociais em virtude da sua produção material, produzem, também, os princípios, as ideias, as categorias de acordo com as suas relações sociais. Assim, essas ideias, essas categorias são tão pouco eternas, quanto as relações sociais que as exprimem. Elas são produtos históricos e, por isso, são transitórias no seu tempo. Todo o discurso de Marx, relativo a essa questão, nos remete ao seu apelo para que se considere a determinação recíproca da subjetividade e objetividade na constituição da vida social dos homens. Isto significa que as relações que compõem a produção são necessariamente relações sociais e estas, por sua vez, pressupõem a existência de homens que produzem em sociedade e que só podem viver em sociedade.

Porém como Proudhon considera que as categorias econômicas sejam fatores independentes e que a realidade social pode ser transformada pela manipulação apenas intelectual, ele não apreende a historicidade concreta do modo de produção capitalista e, portanto, não percebe as suas contradições. É por isso que, de acordo com a dialética proudhoniana, que não passa de uma simplificação extrema de Hegel, toda categoria econômica tem um lado bom e um lado mau, isto é, uma vantagem e uma desvantagem. O que se deve fazer é conservar o lado bom e eliminar o lado mau. Essa distinção dogmática é o que constitui o movimento dialético para Proudhon.

\section{A dialética distorcida de Proudhon}

Proudhon excluiu o melhor da dialética de Hegel ao não considerar a historicidade do homem. Com isso, ele adulterou o próprio conceito hegeliano de síntese, quer dizer, de superação das contradições. Para ele, a superação das contradições do sistema capitalista não seria a passagem revolucionária para um novo sistema social de produção e sim a eliminação do lado mau de qualquer categoria econômica que esteja em contradição com o seu lado bom. Nessa ótica a escravidão, por exemplo, também é uma categoria econômica e tem os seus dois lados. Deixando o lado mau e falando do bom - o fruto do seu trabalho, que leva a progressos industriais, comerciais, etc. - a escravidão está justificada. Pergunta Marx: "como fará o Sr. Proudhon para salvar a escravidão? Colocará o problema: conservar o lado bom desta categoria econômica e eliminar o lado mau" (MARX, idem, p. 108).

Marx comenta que Proudhon realiza um verdadeiro malabarismo com a dialética hegeliana, pois é errôneo - e contraditório à dialética - supor que é possível abolir o aspecto mau de uma determinada categoria preservando seus valores positivos. Mesmo porque as contradições próprias de uma época histórica não são manchas ordinárias que podem ser abolidas simplesmente pensando na eliminação do lado mau. Dessa forma a dialética de Proudhon renega a de Hegel, aliás, "a dialética não é mais o movimento da razão absoluta. Não há mais dialética; há no máximo a moral pura"7(MARX, Idem, p. 110). O resultado disso, segundo Marx, é

\footnotetext{
${ }^{7}$ Como a dialética para Proudhon resume-se nos lados bom e mau das categorias, ele "atribui, arbitrariamente, a qualidade de veicular a correção dos inconvenientes da categoria que é necessário depurar. Assim, os impostos corrigem, a crer-se no Sr. Proudhon, os inconvenientes do monopólio; a balança comercial, os dos impostos; a propriedade fundiária, os do crédito" (MARX, 1982, p. 109). Num tom bastante irônico, Marx diz que "tomando,
} 
que para Proudhon não há mais história: nem como desenvolvimento da idéia, nem a profana, nem a história sagrada das categorias, uma vez que não há o novo, a síntese; não há a fusão das contradições numa nova categoria.

Referindo-se ao critério da totalidade, Marx diz que as relações de produção numa determinada sociedade constituem um todo, um complexo social. No entanto, Proudhon não toma o complexo e sim faz abstrações quando considera as relações econômicas como fases sociais "que se engendram umas às outras, que resulta umas das outras como a antítese resulta da tese, e que realizam, na sua sucessão lógica, a razão impessoal da humanidade" (MARX, Idem, p. 107). Dessa forma, torna-se inviável uma análise da particularidade histórica do capitalismo, pois para isso "o Sr. Proudhon só poderá explicá-la recorrendo a todas as outras relações da sociedade que, no entanto, ele ainda não engendrou pelo seu movimento dialético" (MARX, Idem, p. 107).

Para Marx, o que constitui o movimento dialético "é a coexistência de dois lados contraditórios, sua luta e sua fusão numa categoria nova" (MARX, Idem, p. 109). Desta forma, o todo não é somatório das partes e sim processualidade composta de multiplicidades e diferenciações cuja gênese ocorre na atividade produtiva dos homens. É por isso que, para Marx, não há uma história própria da política, da arte, da religião, etc., uma vez que todos esses complexos sociais são decorrentes, em última instância, da atividade produtiva, embora haja - após a sua geração - um efeito retroativo de tais complexos sobre a base produtiva.

É esse o processo unitário da história, ou seja, só há a história dos homens que é justamente a história da processualidade do ser nos seus diversos ritmos de mudanças. Tais mudanças ocorrem de acordo com o modo de produção e reprodução da vida social dos homens. A totalidade é justamente o conjunto desses complexos sociais que são criados e modificados pelos próprios homens numa dialeticidade histórica.

\begin{abstract}
As forças produtivas são o resultado da energia prática dos homens, mas esta mesma energia é circunscrita pelas condições em que os homens se acham colocados, pelas forças produtivas já adquiridas, pela forma social anterior, que não foi criada por eles e é produto da geração precedente. $O$ simples fato de cada geração posterior deparar-se com forças produtivas adquiridas pelas gerações precedentes, que lhes servem de matéria prima para novas produções, cria na história dos homens uma conexão, cria uma história da humanidade, que é tanto mais a história da humanidade quanto mais as forças produtivas dos homens, e, por conseguinte, as suas relações sociais adquiram maior desenvolvimento. Conseqüência necessária: a história social dos homens é sempre a história do seu desenvolvimento individual, tenham ou não consciência deste fato. As suas relações materiais formam a base de todas as suas relações ${ }^{g}$ (MARX,
\end{abstract}

desta maneira, as categorias econômicas sucessivamente uma a uma e fazendo desta o antídoto daquela, o Sr. Proudhon consegue construir, com esta mistura de contradições e antídotos de contradições, dois volumes de contradições, a que dá, com justa razão, o título de Sistemas das Contradições Econômicas" (MARX, idem, p. 109).

8 Mais tarde, no Prefácio de 1859 de Para a Crítica da Economia Política, Marx vai destacar e desenvolver essa sua idéia de totalidade. Referindo-se às relações de produção que correspondem a cada etapa do desenvolvimento das forças produtivas, diz Marx: "A totalidade destas relações de produção forma a estrutura econômica da sociedade, a base real sobre a qual se levanta uma superestrutura jurídica e política, e à qual correspondem formas sociais determinadas de consciência. O modo de produção da vida material condiciona o processo em geral da vida social, política e espiritual" (MARX, "Para a Crítica da Economia Política, Prefácio de 1859", Coleção Os Pensadores, 1978, p. 129 - 130) 
"Carta de Marx à P.V. Annenkov", anexo à Miséria da Filosofia, 1982, p. 207. Grifos do autor).

Essa longa citação, em que pese às inúmeras questões que dela podemos extrair, é para destacar que o homem é produtor da sua própria vida social, e afastar o preconceito, proporcionado pelo materialismo vulgar, de se reduzir a teoria social de Marx a um determinismo econômico. Paulo Neto, na defesa da teoria marxiana, diz que a teoria social de Marx "não se instaura como um somatório enciclopédico de saberes autônomos (história, economia, política, etc.). Contrariamente, é uma estrutura teórica unitariamente articulada sobre a perspectiva da categoria fundamental da realidade social, a totalidade" (PAULO NETO. "Introdução" à Miséria da Filosofia, 1982, p. 32. Grifos do autor). O autor comenta ainda que a concepção da totalidade em Marx não é apenas um imperativo metodológico, mas resulta das suas investigações histórico-sociais concretas acerca da estrutura econômico-social da sociedade capitalista.

Lukács (1979) também faz essa mesma defesa em relação a Marx. A esse respeito ele comenta que quando Marx afirma, em Para a Crítica da Economia Política, que "não é a consciência dos homens que determina o seu ser; ao contrário, é o seu ser social que determina sua consciência", isso não significa que a consciência seja vista unilateralmente como um produto direto da estrutura econômica, e sim do complexo social, resultante da própria ação humana, que forma uma totalidade em cada período e modo de produção. Por conseguinte, a totalidade se renova constantemente e está relacionada a outras totalidades anteriores, quer dizer, as relações sociais de cada período histórico constituem um todo, e cada parte deste todo está em determinação mútua com as demais. Lukács adverte que "a determinação da consciência pelo ser social, portanto, é entendida em seu sentido mais geral. Só o marxismo vulgar... é que transformou essa determinação numa declarada e direta relação causal entre economia... e ideologia" (LUKÁCS, 1979, p. 41). No entanto, o processo total da sociedade não é nunca dirigido por uma posição finalística; não existe uma teleologia geral ou na história, como concebia Hegel, mas apenas causal: "todo evento decorre de posições teleológicas individuais [...]" (LUKÁCS, 1978, p. 10). Porém o resultado, a síntese dessas múltiplas determinações tem conseqüências para todos os processos sociais que vão determinar novas ações. É por isso que Lukács diz que "o processo global da sociedade é um processo causal [...] mas não é jamais objetivamente dirigido para a realização de finalidades" (LUKÁCS, 1978, p. 10) no sentido, como já frisamos, de uma teleologia geral, independente das posições teleológicas dos homens.

Como para Marx as relações sociais de cada sociedade constituem um todo, cujas partes que o compõem estão em relação e em determinação mútuas, torna-se impossível a aplicação da dialética proudhoniana, quer dizer, é impossível eliminar somente o lado mau de uma categoria e deixar-lhe o lado bom, uma vez que os dois lados são aspectos distintos de uma mesma situação. A contradição das posições de Proudhon é tão imensa que a sua dialética "renega a de Hegel" (MARX, 1982, p. 110), suprime a dialética e a própria história dos homens, pois, "toda a bagagem econômica do Sr. Proudhon é transportada pela locomotiva da Providência [...] fim providencial - eis as grandes palavras que se utilizam hoje para explicar a marcha da história" (MARX, Idem, p114).

É por isso que Proudhon não percebe a historicidade concreta da vida social dos homens. Aliás, segundo Marx, os economistas enveredam pelo mesmo caminho 
do método metafísico e idealista, uma vez que reduzem a economia política a um esquema de abstrações do espírito, a um esquema de idéias puras. Dessa forma, as relações econômicas - consideradas como leis imutáveis, como categorias ideais anteriores aos homens - tornam-se "eternidades imutáveis e imóveis, não há história; há no máximo a história na ideia, ou seja, a história que se reflete no movimento dialético da razão pura" (MARX, Idem, p. 111).

Dessa forma, com um jogo sofístico, "os economistas têm procedimentos singulares. Para eles, só existem duas espécies de instituições, as artificiais e as naturais" (MARX, Idem, p. 115). As instituições artificiais são as da feudalidade; e as naturais são as da burguesia. Assim como os teólogos estabelecem dois tipos de religião (a religião que eles adotam, que é a emanação de Deus; e as outras, que são invenção dos homens) também os economistas estabelecem esses dois tipos de instituições. Ao considerar as relações da produção burguesa como naturais, "os economistas dão a entender que é nestas relações que a riqueza se cria e as forças produtivas se desenvolvem segundo as leis da natureza [...]. São leis externas que devem, sempre, reger a sociedade. Assim, houve história, mas já não há mais" (MARX, Idem, p.115). Houve história porque houve o feudalismo, com as suas relações de produção diferentes das que constituem a sociedade burguesa. Porém não há mais porque os economistas querem fazer das relações capitalistas categorias naturais e eternas.

\section{Para concluir}

Pelo exposto, podemos verificar nas colocações de Marx a sua radical oposição não somente à Proudhon, mas também aos demais economistas que não compreenderam o caráter histórico das determinações sociais na vida dos indivíduos. Dessa forma, todos eles "caem" num método metafísico ao analisar a realidade sem considerar esse caráter histórico da vida social dos homens; é essa a principal metafísica da economia política.

As investigações de Marx nos mostram que a produção é o primado da história. No entanto, chamamos a atenção para não interpretarmos as colocações de Marx ao nível de uma dialética abstrata, uma vez que é justamente o que ele combate. Para ele, as contradições sociais não se reduzem a categorias de antagonismos sem um salto para o novo, pois desta forma cairíamos num movimento abstrato. $O$ que se deve levar em conta são os caracteres específicos e as condições sociais que diferenciam os complexos sociais em cada etapa histórica. Dessa forma, o princípio histórico objetivo não se apresenta como um referencial externo, nem tampouco como um mero dado, mas é pensado a partir da práxis, da atividade humana. É por isso que, para Marx, as categorias econômicas se põem como esfera da realidade histórico-social, uma vez que esta é constituída por atos dos homens, pela práxis social.

As ideias de Marx, desenvolvidas em suas obras de juventude, incluindo a Miséria da Filosofia, serão posteriormente intensificadas, recebendo uma formulação clássica na sua obra $O$ Capital. Porém, ao longo dos seus escritos ele esteve permanentemente voltado para o estudo dos fenômenos sociais, com base numa concepção materialista da história. Não há uma separação em suas idéias de juventude com as de maturidade e sim um constante aprimoramento nas suas investigações e princípios metodológicos. Em A Miséria da Filosofia, diz Paulo Neto, 
surge o primeiro desenho do projeto teórico de Marx sobre a "análise de conjunto do modo de produção capitalista" (PAULO NETO. "Introdução" à Miséria da Filosofia, 1982, p. 30). Nela, a crítica da economia política aparece como um dos resultados da investigação histórico-social concreta. Portanto, o fato de, na Miséria da Filosofia, Marx não ter realizado uma crítica na sua riqueza e amplitude com os quais fez na sua obra $O$ Capital, isso "não retira ao historiador das idéias marxianas o direito - e o dever - de reconhecer que, já na Miséria da Filosofia, Marx se coloca como o pensador que operou a mais radical e decisiva revolução teórico-social dos tempos modernos" (PAULO NETO, Idem, p. 32). 


\section{Referência}

FEDOSSEIEV, P. N. e outros. Karl Marx - Biografia. 1. ed., Lisboa: Avante, 1983.

KOLAKOWSKI, Leszek. Lãs Principales Corrientes Del Marxismo. vol. I: Los Fundadores. Tradução de Jorge Vigil. 1 ${ }^{\text {a }}$ ed., Madrid: Alianza Universidad, 1980.

LUKÁCS, György. "As Bases Ontológicas do Pensamento e da Atividade do Homem", IN: Revista Temas, n ${ }^{0}$ 04. Tradução de Carlos Nelson Coutinho, 1ª ed., São Paulo: 1978.

LUKÁCS, György. Os Princípios Ontológicos Fundamentais de Marx. Tradução de Carlos Nelson Coutinho, $1^{\text {a }}$. ed., São Paulo: Livraria Ciências Humanas, 1979.

MARX, K. e ENGELS, F. A Ideologia Alemã. Tradução de José Carlos Bruni e Marco Aurélio Nogueira, $4^{\mathrm{a}}$. ed., São Paulo: HUCITEC, 1984.

MARX, K. Miséria da Filosofia. Tradução de José Paulo Neto. $1^{a}$. ed., São Paulo: Livraria Ciências Humanas, 1982.

MARX, K. "Carta de Marx à P.V. Annenkov", anexo à Miséria da Filosofia, Trad. José Paulo Neto. São Paulo: Ciências Humanas, 1982.

MARX, K. "Para a Crítica da Economia Política - Introdução e Prefácios de 57 e 59", IN: Marx - Os Pensadores. Tradução de Edgar Malagodi, Leandro Konder e Outros. 2a . ed,. São Paulo: Abril Cultural, 1978.

PAULO NETO, José. "Introdução à edição brasileira da obra de Marx", IN: Miséria da Filosofia. 1ª ed., São Paulo: Ciências Humanas, 1982.

Contribuição dos autores:

$\mathrm{O}$ artigo foi redigido e revisado conjuntamente pelos autores Adauto Lopes da Silva Filho e Fátima Maria Nobre Lopes. Ambos aprovaram a sua versão final.

Autor(a) para correspondência: Adauto Lopes da Silva Filho, Universidade Federal do Ceará, Instituto de Cultura e Arte, Rua Doutor Abdenago Pici, CEP 60440-614, Fortaleza - CE, Brasil. adautoufcfilosofia@gmail.com 